(Received on 30 March 2014; Accepted on 14 August 2015)

\begin{abstract}
The progress of solar (photovoltaic) cells over the years is reported here. The selection and engineering of materials that have been used in the first to the fourth generation solar cells present salient features on why such newer materials were or would be introduced are discussed. Our perspectives to look beyond silicon as solar cell materials are presented. The issues of toxicity and earth-abundance of elements in forming active materials of solar cells are discussed. Measurement parameters, methods to improve performance, and mechanism of operation of different solar cells have also been discussed.
\end{abstract}

Keywords: Solar Cells; Photovoltaic Devices; New Materials for Solar Cells

\section{Introduction: Use of Solar Energy}

It is now well-documented that several factors such as increasing energy needs, rapid decrease in energy sources from fossil fuels, and urgent requirement to protect the environment for the future generations, prompted the search for green and renewable energy sources more than ever. At the moment, almost $80 \%$ of world's energy supplies come from burning of fossil fuels. Apart from their limited reserve that would last for another couple of decades, use of these resources has been a major cause behind degradation of the environment such as global warming, acid rains, increase in carbon dioxide content in the environment, smog, etc. that affect all kinds of habitats cutting across borders and boundaries of countries and continents. Green energy resources such as solar, wind and tidal, and hydropower offer a supplement to the fossil fuels so that the usage of conventional source of energy can be restricted. All these renewable, nonconventional, and green resources of energy produce little or no pollution or greenhouse gases and also, more importantly, have unlimited resources. With the urgency to use such green energy resource, it is important that researchers tap all possible sources of renewable energy. While each form of energy source is relevant and applicable to a geographical location or so, every quantum of such green energy will be beneficial to cater energy requirement of the future.

Among the green energy resources, sunlight is the most abundant, renewable, and readily available source. Another primary advantage of this source of energy is that it can be exploited even in remote areas, where supply of electricity is limited for various reasons. While both thermal and photonic components of solar spectrum could in principle be converted to electricity, photovoltaic (PV) solar cells were considered for immediate use since they were being successfully used in spacecraft for many years that studied terrestrial science. At present, photovoltaic solar cells are of relevance due to their rapid growth amounting to a total global capacity of 67,400 megawatts (MW) at the end of 2011 that represents $0.5 \%$ of worldwide electricity supply (http:// www.epia.org/home/). The foremost challenge for large-scale commercial applications of photovoltaic solar cells is their high manufacturing cost. The solar panels are based on mostly monocrystalline, polycrystalline, or amorphous silicon, cadmium

*Author for Correspondence: E-mail: sspajp@iacs.res.in 
telluride, and copper indium gallium selenide/sulphide. Processing of active materials in the solar cells requires expensive instruments leading to an increase in the manufacturing cost. The fast growth of the PV market is sustainable if the manufacturing cost could be reduced to compete with the cost per watt (or $\$ / \mathrm{W}$ ) that the conventional mode of power generation offers. It is hence appropriate to look for newer materials which may lower the manufacturing cost reducing the $\$ / \mathrm{W}$ of the solar cells. Another route to reduce the $\$ / \mathrm{W}$ has been to improve the power conversion efficiency (PCE), i.e., the percentage of light energy getting converted to electrical energy, of a photovoltaic device with a proper choice of material(s). Different technologies have been developed to achieve a balance between the manufacturing cost of PV solar cells and their efficiency to compete with the cost of electricity from fossil fuels.

\section{Evolution of Solar (Photovoltaic) Cells}

While the principle of solar cells in the form of photovoltaic effect was discovered by French physicist Becquerel in 1839, a practical photovoltaic cell was developed in 1954 at Bell Laboratories (Chapin et al., 1954). They used a diffused silicon $p n$-junction as a solar cell that yielded an efficiency of $6 \%$. Since then, the quest for new materials that would offer an improved efficiency continued. Most of the semiconductor materials that researchers targeted had a bandgap of $1.0 \mathrm{eV}$ or more, so that visible range of solar spectrum is absorbed for conversion to electricity. Shockley and Queisser established that a single-junction solar cell could reach a maximum efficiency of $30 \%$ for an optimum band gap material (Shockley and Queisser, 1961). On the basis of the materials used, mechanism involved, fabrication method, and the manufacturing cost of solar cells, researchers have categorized the generation of solar cells.

\section{First Generation Solar Cells}

The first generation solar cells are based on single crystalline and multicrystalline silicon. Crystalline silicon solar cells derived their name from the way they were made. The monocrystalline silicon solar cells are made from thin wafers that were cut from a singular continuous crystal specially grown for this purpose. Polycrystalline silicon solar cells are made by melting the silicon material and pouring it into a mould. Since the discovery at Bell Laboratories, the crystalline silicon solar cell efficiency has reached up to $24 \%$ (Green et al., 2005). The efficiency of single $p n$-junction crystalline silicon solar cells could reach up to the theoretically predicted limit of $30 \%$ (Shockley and Queisser, 1961). In India, much research has been carried out in this direction with microcrystalline and polycrystalline silicon (Ray et al., 1988; Sastry et al., 1985). At present, silicon solar cells cover roughly $86 \%$ of the PV market due to their relatively high conversion efficiency. The efficiency of commercial products in modules typically reach about $15-20 \%$ (http://www.solarplaza.com/top10-crystalline-moduleefficiency/, 2012). The manufacturing techniques that are used to produce first generation solar cells are inherently expensive, resulting in years to pay back their purchasing cost.

\section{Second Generation Solar Cells}

In second generation solar cells, thin film technology has been used. These solar cells are thinner, flexible to some extent, and less expensive as compared to the first generation solar cells. The solar cells have a light-absorbing thickness of $10 \mu \mathrm{m}$ as compared to 200-300 $\mu \mathrm{m}$ used for crystalline silicon solar cells. Semiconductor materials for the second generation solar cells ranged from amorphous and micromorphous silicon (Carlson and Wronski, 1976; Song and Anderson, 2000) to binary or quaternary semiconductors, such as cadmium telluride (CdTe) (Britt and Ferekides, 1993), gallium arsenide (GaAs) (Olson et al., 1990) and copper indium gallium selenide (CIGS) (Sites and Liu, 1996). The use of direct band gap semiconductors, in contrast to indirect band gap silicon, lowered the cost of photoabsorbing materials since thinner-films of such semiconductors were enough to absorb sufficient amount of solar light for photoconversion. Thin-film solar cells based on such materials have shown signs of dominance in photovoltaic market covering $18 \%$ of the global photovoltaic market. This type of solar cells is stable and has been commercialized with a module efficiency of $\sim 20 \%$. Though the power conversion 
efficiency of these solar cells is less than that of crystalline silicon solar cells, the second generation solar cells are expected to be cost-effective as compared to the cost of electricity generation from fossil fuels. A comprehensive review on this type of solar cells can be found in the literature (Green et al., 2005). Unfortunately, there are still some unresolved issues in commercializing these solar cells in terms of production in mass quantities at a competitive price and at a reasonable efficiency level.

\section{Third Generation Solar Cells}

Organic semiconductors and conjugated polymers, with its success in light-emitting diodes and flat panel displays, are being considered as advanced materials for the third generation solar cells. Such solar cells, still at the laboratory level, are based on thin-films of the materials. With the difference in operation mechanism, organic/polymeric solar cells can be subclassified into organic photovoltaic devices (OPV) and plastic (polymer) solar cells (Wohrle and Meissner, 1991; Peumans et al., 2003; Yang et al., 2005; Li et al., 2005; Brabec et al., 2001; Park et al., 2009), photoelectrochemical solar cells (Keis et al., 2002; Gratzel, 2001), and organic dye-sensitized solar cells (DSSC) (Oregan and Gratzel, 1991; Law et al., 2005). Overall, the power conversion efficiency of DSSCs has reached more than $12 \%$ in the lab-scale (Yella et al., 2011). Commercial applications of DSSCs may however be limited due to the liquid electrolyte used in the cells. In organic or polymeric PV devices, bulkheterojunctions based on regioregular poly(3hexylthiophene) $\left(\mathrm{P}_{3} \mathrm{HT}\right)$ as a hole-transporting material and a fullerene derivative, namely phenylC61-butyric acid methyl ester (commonly known as PCBM), as an electron-transporting material are one of the most-studied systems (Li et al., 2005; Scharber et al., 2006). Recently, some low band gap polymers are being used to harvest near-IR spectrum of solar energy (Albrecht et al., 2012; Peet et al., 2007). In organic or polymeric solar cells, device operation involves photogeneration of excitons, exciton dissociation or charge separation, and carrier transport to the opposite electrodes. Some of the advantages of organic or polymeric PV devices are (1) films are spun from solutions, (2) fabrication of large-area devices is possible, (3) the requirement and hence the cost of the materials is low, and (4) devices can be fabricated on flexible electrode substrates. The major disadvantage of this class of semiconductor is that the carrier mobility in these materials is often low hindering efficient flow of holes and electrons to the opposite electrode. Nonetheless, third generation solar cells are expected to enter the market soon.

\section{Fourth Generation Solar Cells}

Materials engineering being one of the fastest and rapidly growing fields of research, newer materials offer themselves as supplements or complements in device fabrication. A bright example in this direction is the inclusion of (inorganic) semiconducting quantum dots in organic/polymeric photovoltaic devices and dye-sensitized solar cells. Such devices, often termed as nanophotovoltaics, are considered to be the fourth generation solar cells and have a high prospect as a future of solar cell technology. Here, the advantages of semiconducting quantum dots have been brought to supplement performance of organic and polymeric solar cells. Some of the proven examples in this direction are quantum dot-sensitized solar cells (QDSSC) (Kamat, 2008; Nozik, 2002; Sun et al., 2008), quantum dot-based thin film solar cells (Panthani et al., 2008; Ip et al., 2012), and hybrid bulk-heterojunction solar cells (Huynh et al., 2002). $\mathrm{Xu}$ et al. have reported QDSSCs based on CdSe nanoparticles with an efficiency of $4.54 \%$ (Xu et al., 2012). Sargent's research group has reported an efficiency of $7 \%$ in solar cells based on inorganic quantum dots (Ip et al., 2012). Researchers across the globe are focusing on a range of materials and methods to fabricate devices in order to improve this emerging technology to achieve a proper balance between the manufacturing cost and the efficiency of solar cells.

Recently, a new type of solar cells based on organometal halide perovskite materials has attracted much attention due to high efficiency and stability. The efficiency of methylammonium lead halide perovskite sensitized solar cells reached $16.2 \%$ within a very short period of research and development (Kim et al., 2012; Lee et al., 2012; Burschka et al., 2013; 
Liu et al., 2013). In Fig. 1, we have shown a bar diagram representing efficiencies of different types of solar cells. Some commonly used active materials in each type of solar cells are also mentioned. Fig. 1 shows that the efficiencies of photovoltaic devices based on the new materials are yet to match that of silicon solar cells. Researchers across the globe are still optimistic due to the rapid progress in the parameters of these higher-generation solar cells, in addition to low material production cost of such solar cells.

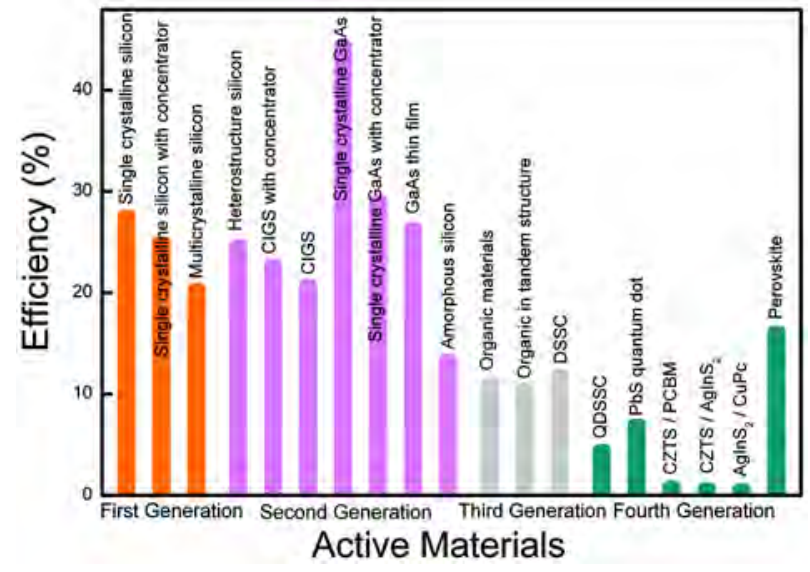

Fig. 1: Efficiency of different generations and types of solar cells along with some commonly used active materials in each type of solar cells. Data were obtained from Research Cell Efficiency Records, National Center for Photovoltaics (NCPV) at National Renewable Energy Laboratory (NREL), Golden, Colorado, USA (http://www.nrel.gov/ncpv/, 2014)

\section{Parameters of Solar Cells}

\section{Open-circuit Voltage $\left(V_{O C}\right)$}

The photovoltage generated across the two terminals when the circuit remains open is known as the opencircuit voltage $\left(V_{\mathrm{OC}}\right)$. The difference in the quasi Fermi levels determines the $V_{\mathrm{OC}}$ of a solar cell. Generally, photoexcited electrons go through a thermalization process to lose their potential energy to the phonons until the electrons reach the lowest energy level of the conduction band (in case of inorganic semiconductors) or the lowest unoccupied molecular orbital (LUMO, in case of organic semiconductors). Thus, the band gap of the semiconductor is often regarded as a measure of achievable photovoltage. A higher band gap could result in a higher photovoltage. In the same context, a higher band gap material cannot absorb sufficient light in the visible region. There should hence be an optimum band gap for an efficient performance of photovoltaic devices under a white light illumination. Shockley and Queisser calculated the optimum band gap for maximum power conversion efficiency assuming only radiative recombination under solar radiation (Shockley and Queisser, 1961). They obtained a power conversion efficiency of $30 \%$ for a semiconductor with a band gap of $1.12 \mathrm{eV}$. Interestingly, the value matches quite well with the band gap of silicon.

\section{Short-circuit Current $\left(J_{S C}\right)$}

When the cell is short-circuited, the current which flows through the external circuit is known as the short-circuit current $\left(I_{\mathrm{SC}}\right)$. To achieve a high value of $I_{\mathrm{SC}}$, we should have an active material of high optical absorption coefficient along with high carrier mobility. The $I_{\mathrm{SC}}$ of a solar cell also depends on the incident light intensity and the cell area. It is hence effective to calculate short-circuit current density $\left(J_{\mathrm{SC}}\right)$ under a given solar illumination to compare short-circuit current of different devices based on a range of materials.

\section{Fill Factor (FF)}

Since the $I-V$ characteristics of a solar cell under illumination condition passes through the fourth quadrant, the power, which is a product of the voltage and the current, in this quadrant is negative implying that one would be able to draw power from the device. In Fig. 2, the current-voltage characteristics of a typical solar cell under dark and under certain illumination have been shown. In the $I-V$ characteristics, we can obtain a point in the fourth quadrant that corresponds to maximum power achievable $\left(P_{\mathrm{Max}}\right)$, that is, product of the voltage and the current is highest at this point. The point is called as the maximum power point for which there are maximum voltage $\left(V_{\mathrm{Max}}\right)$ and maximum current $\left(I_{\mathrm{Max}}\right)$. The shape of the $I-V$ curve in the fourth quadrant is very crucial to maximize the product at the maximum 


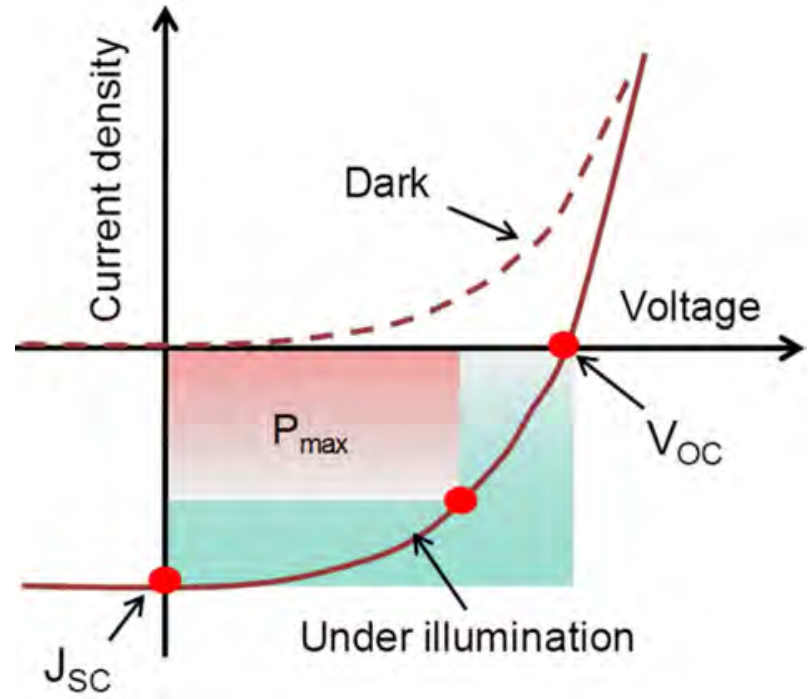

Fig. 2: Current density versus voltage $(J-V)$ characteristics of a typical solar cell under dark (dashed line) and illumination (solid line) conditions. Parameters of solar cells such as the open-circuit voltage $\left(V_{O C}\right)$, the short-circuit current density $J_{S C}$, and the maximum power point $P_{\text {Max }}$ are shown on the $J-V$ curve

power point. This maximum area is higher when the $I-V$ curve resembles a rectangle with sides of $V_{\mathrm{OC}}$ and $J_{\mathrm{SC}}$. The ratio between these two areas is known as the fill factor $(F F)$ which represents a measure of the shape of $I-V$ characteristics in the fourth quadrant, that is, the fill factor is defined as:

$$
F F=\frac{I_{\text {max }} \times V_{\text {max }}}{I_{\mathrm{SC}} \times V_{\mathrm{OC}}}
$$

Using this fill factor, power conversion efficiency (PCE) of a solar cell can be defined as :

$$
\begin{gathered}
\operatorname{PCE}(\eta)=\frac{P_{\text {max }}}{P_{\text {in }}} \times 100=\frac{I_{\text {max }} \times V_{\text {max }}}{P_{\text {in }}} \times 100 \\
=\frac{I_{\mathrm{SC}} \times V_{\mathrm{OC}} \times \mathrm{FF}}{P_{\text {in }}} \times 100,
\end{gathered}
$$

where $P_{\text {in }}$ is the incident light power. Since the power conversion efficiency $(\eta)$ depends on the incident wavelength and intensity, $\eta$ is measured under a simulated solar spectrum. In order to compare the efficiencies of different solar cells, a standard solar irradiance is considered. The most common standard irradiance is AM1.5 (air mass $1.5 \sim 1$ Sun) and this standard illumination $\left(\sim 100 \mathrm{~mW} / \mathrm{cm}^{2}\right)$ can be achieved by most commercial solar simulators. The physical principles behind the operation of different types of solar cells are generally different. The current-voltage characteristics of well-performing cells are however similar and can be characterized and compared with each other in terms of $\mathrm{FF}, V_{\mathrm{OC}}$, and $I_{\mathrm{SC}}$.

\section{Power Conversion Efficiency}

Power conversion efficiency (PCE) is the most important parameter of solar cells. It is defined as the percentage of maximum output of electrical power to the incident optical power. The generated output electrical power is the product of the generated photovoltage and the photocurrent. Therefore, in order to achieve a high PCE, one should have a high photovoltage as well as a high photocurrent under an illuminated condition.

\section{Thin-film (Photovoltaic) Solar Cells: Device Architecture}

The basic components of thin-film solar cells are an active layer and a pair of electrodes. The active layer may comprise one or several materials. The active layer absorbs sunlight; the two electrodes which have in general dissimilar work-functions collect carriers to yield photocurrent in the external circuit. The electrodes should form ohmic contacts with the active layer that is next to the electrode so that the interfaces do not impose barriers for the charge carriers to reach the electrodes. Depending on the materials used in the active layer and the electrodes, several device architectures can be formed:

- Metal $_{1} /$ Semiconductor/Metal 2 (Schottky junction)

- $\quad \mathrm{Metal}_{1} / p$-type semiconductor/n-type semiconductor/metal ${ }_{2}$-based on the same semiconductor material (Homojunction)

- $\quad \mathrm{Metal}_{1} / p$-type semiconductor/n-type semiconductor/metal 2 -based on two different semiconductor materials (Heterojunction) 
- $\quad$ Metal $_{1} / p$-type semiconductor/insulator/n-type semiconductor/metal 2 ( $p-i-n$ junction)

- Junction ${ }_{1}$-Junction $_{2}$-Junction $_{3}$ (tandem solar $^{-}$ cells)

When a $p$-type semiconductor and an $n$-type semiconductor are brought in contact, electrons from the $n$-type semiconductor diffuse to the $p$-type semiconductor due to a concentration gradient of the carriers. Similarly, holes from the $p$-type material diffuse to the $n$-type semiconductor. During diffusion process, the carriers leave behind uncompensated immobile charges at the regions from where they diffused. Electrons leave donor ions (+) at the $n$-type region and holes leave acceptor ions (-) at the $p$-type region of the $p n$-junction. These immobile charges create an electric field that forms a potential barrier which finally opposes the carriers to diffuse further. The region across the junction where the electric field appears is termed as the depletion region.

Under illumination, electron-hole pairs (excitons) form in both sides of the junction. These photogenerated electron-hole pairs if diffused to the junction become dissociated due to the electric field at the junction. (In case of a single layer structure based on a bulk semiconducting material, the excitons can be dissociated just after the photogeneration). Now, the holes flow through the $p$-type material and electrons flow through the $n$-type material to the opposite direction. These separated electrons and holes form quasi fermi levels at both sides of the junction and the difference between these two quasi fermi levels is the origin of open-circuit voltage $\left(V_{\mathrm{OC}}\right)$ of the solar cells. When contacts are made in the external circuit, a short-circuit current $\left(I_{\mathrm{SC}}\right)$ flows through the circuit without any applied voltage. In Fig. 3, a schematic representation of a $p n$-junction, depletion region, bandbending, and the origin of $V_{\mathrm{OC}}$ have been depicted.

The operation mechanism of organic photovoltaic devices differs from that of inorganic semiconductor solar cells. In organic PV devices, the built-in electric field due to the electrodes acts only near the interfaces. Since the active region of an organic device consists of two materials, the interface between the materials provides the required energy-offset to

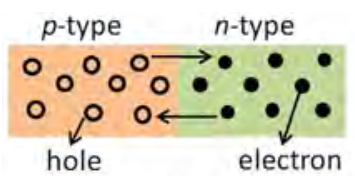

(A)

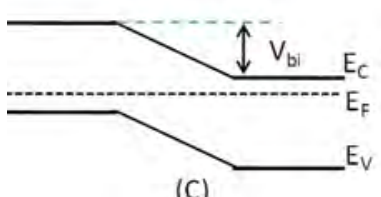

(C)

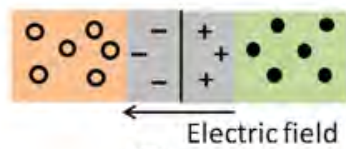

(B)

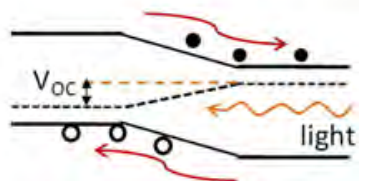

(D)
Fig. 3: Schematic representations of a $p n$-junction formation showing (A) diffusion of carriers under contact, (B) formation of a depletion region, (C) band-bending at the junction, and (D) movement of carriers under an illuminated condition and the origin of $V_{\mathrm{OC}}$

dissociate excitons, that is, after photogeneration of excitons, they may diffuse to the donor-acceptor interface. If the difference in electron affinities or the difference in ionization potentials or the difference in both the levels of the donor and acceptor materials is higher than the exciton binding energy, the excitons in the organic PV devices become dissociated.

\section{Thin-film (Photovoltaic) Solar Cells: Materials Engineering}

As has been stated, device operation of organic or polymeric thin-film solar cells involves three steps, namely, (1) exciton generation due to illumination, (2) exciton dissociation or charge separation, and (3) carrier transport to the opposite electrodes. Since the three steps occur in a sequence, efforts have been made to enhance efficiency or output of each of the steps. Generation of excitons expectedly depends on matching of optical absorption spectrum of the active materials with the solar illumination. Active materials are hence chosen accordingly. Exciton dissociation or charge separation, which occurs at the interface between a donor and an acceptor layer, takes place due to the internal field that develops owing to the difference of energy levels at the interfaces. Carrier transport, the third step, is directed by the internal field generated by the difference in work-functions of the two electrodes. Apart from the electric-field, mobility of charge carriers plays a major role in determining the short-circuit current of photovoltaic 
devices.

Considering the limitation of organic and polymeric materials in each of the steps of device operation, efforts have been made to incorporate quantum dots or nanostructures in photovoltaic devices. In other words, the fourth generation solar cells involving nanostructures in organic devices are meant to overcome the drawbacks of the third generation solar cells. In solar cells based on organic and inorganic semiconductors or hybrid materials, advantages of the both types of materials are clubbed together. Some of the advantages can be listed as follows:

- One of the major advantages of inorganic nanocrystals is their broad absorbance. Extinction coefficient of some nanocrystals is high $\left(\sim 10^{4} \mathrm{~cm}^{-1}\right)$. Band gap of the nanocrystals can be tuned through quantum confinement to suit the need of photoabsorption in a wider spectral region.

- Wannier excitons in nanocrystals have a lower binding energy than Frenkel excitons that form inorganic molecules upon photoillumination. This is due to the fact that the electron and the hole of a Wannier exciton can reside in different molecules as opposed to Frenkel excitons, where the two carriers reside in the same molecule. Typical binding energy of excitons in inorganic quantum dots (diameter $\sim 2-4 \mathrm{~nm}$ ) is in the range of 0.05 to $0.2 \mathrm{eV}$; whereas, Frenkel excitons in organic molecules have a binding energy of 0.1 to $1.0 \mathrm{eV}$.

- There is a possibility of formation of multiple excitons in nanocrystals from a single photon (Binks, 2011). The quantum mechanical origin of the process is still under debate.

- Mobility of both types of charges in inorganic nanocrystals is high.

- Most of the quantum dots are very stable under ambient condition.

Fabrication of organic solar cells with inorganic nanomaterials could leap the research on solar cells a step forward. In general, some conjugated polymers are used as a hole-transporting material ( $p$-type) and inorganic nanostructures are used as an electrontransporting material ( $n$-type) or vice versa. The first hybrid solar with sufficient efficiency was reported by Huynh et al. (Huynh et al., 2002). Since then several studies have been reported based on different inorganic nanocrystals such as $\mathrm{CdS}, \mathrm{CdSe}, \mathrm{CdTe}$, $\mathrm{ZnO}, \mathrm{SnO}_{2}, \mathrm{TiO}_{2}, \mathrm{Si}, \mathrm{PbS}, \mathrm{PbSe}$, etc. (Cui et al., 2006; Hines and Scholes, 2003; Holder et al., 2008; Kuo et al., 2008; Kuwabara et al., 2009; Lutich et al., 2009). Dayal et al. have reported a hybrid solar cell with an efficiency of 3.2\% under AM 1.5 irradiation using a low band gap polymer and CdSe nanoparticles (Dayal et al., 2009). One of the disadvantages that the inorganic nanocrystals imposes in photovoltaic devices is that the insulating capping ligands that are necessary to form dispersed solution or ink of the nanocrystals hinder inter-nanocrystal carrier transport.

\section{International Status: Research to Technology}

Country-wise, Taiwan, Germany, China, and USA are the market leaders of this technology. During 2013, with a most likely forecasting scenario, 25 different countries are projected to have $>100 \mathrm{MW}$ of PV demands. India seems to be catching up with a seventh rank (projected for 2013) worldwide.

The solar modules that are commercially available are generally based on crystalline $\mathrm{Si}$, amorphous-Si, CdTe and CIGS materials. Some of the leading companies in this field are Yingli Green, First Solar, Suntech Power Co., SunPower, and so on. Konarka and Mitsubishi have been manufacturing solar modules based on organic photovoltaic devices. In the competing global solar markets, cost reduction and increasing cell efficiencies are the key factors to the module manufacturers to sustain their business or to drive the business to the next level.

Different companies have been trying to increase the ultimate output wattage by engineering the installation procedure of solar panels. Instead of simply collecting the solar light which is just shining the surface of a solar panel, a new technology has been developed with an addition of optical equipment such as lenses and mirrors to focus greater amounts 
of solar energy onto highly efficient solar cells (concentrated solar power, CSP). Although this technique could hike the manufacturing cost slightly, the advantages of CSP over conventional solar panel setups offer a high throughput for further research and development technologies. There are also some upcoming technologies to develop new architectures for solar cell installation. The basic mechanism behind such a technology is that the solar panels keep moving with the sun to acquire extra solar light. Genie Lens Technologies has developed a new route to enhance light absorption of solar panels. A large polymeric transparent sticker is applied to the front of the panels. Microstructures on the polymer stickers are capable of bending and redirecting the sunlight which increases the power output by about $10 \%$ and more.

Manufacturers of other household products are also tapping solar energy in their product. To name a few, automobiles, roofs and facades of buildings, portable electronics, etc. will soon be decorated with solar cells not only to make the products attractive to consumers, but also contribute to renewable energy production in one's own household.

\section{Research Directions Across the World}

The basic aim behind the progressing technology is to make a balance between the manufacturing cost and the module efficiency. As we know, silicon solar cells require a surface coating that increases the cost of the modules. Tonio Buonassisi and his group at MIT developed an alternative in the form of a polymer layer on silicon solar cells that sustained more than $200 \mathrm{~h}$ of continuous operation without any degradation.

Stretchability, in addition to flexibility of polymers has brought a new dimension in the organic solar cell technology. Such a property of polymers would integrate them in textiles, moving parts of machinery, one-time bonding to curved surfaces such the exteriors of buildings, automobiles, and many others.

Scientists from the Swiss Federal Laboratories for Materials Science and Technology have developed thin film solar cells on flexible polymer foils with an efficiency of $20.4 \%$. They used copper indium gallium (di)selenide (CIGS) semiconducting material for the solar cell fabrication. It appears that CIGS has a large potential to provide cost-effective solar panels. The technology is currently awaiting scaling-up for commercial production.

These are more examples of new research directions to improve the efficiency of solar cell modules. Some of the techniques are almost ready for commercial production. In the laboratory scale, much research focuses on new materials and manufacturing processes. Recently, use of earthabundant elements is gaining interest so that the cost of materials becomes low.

\section{Major Contributions from Indian Researchers and Industries}

Maharishi Solar Technology Pvt. Ltd., New Delhi, one of the oldest players in the market, has been manufacturing solar cells based on polycrystalline silicon material. Researchers at IIT Bombay, in National Centre for Photovoltaic Research and Education (NCPRE), have achieved 20-22\% efficiency in single crystal silicon solar cells. The Solar Energy Centre (SEC), a unit of the Ministry of New and Renewable Energy, is providing technical assistance to industries for the development of solar energy products. Moser Baer, in collaboration with CSIR-NPL, New Delhi has developed CIGS-based solar cells with an efficiency of $12-15 \%$. In the arena of dye-sensitized solar cells (DSSCs), IIT Kanpur, CSIR-IICT Hyderabad, and IIT Delhi are working to achieve 6-10\% efficiency.

\section{Thin-film (Photovoltaic) Solar Cells: Our Approach}

\section{Hybrid Core-shell Nanoparticles}

Photoinduced electron transfer from a semiconducting quantum dot to another quantum dot (Tu and Kelley, 2006) or to certain organic molecules has been reported to be ultrafast (Boulesbaa et al., 2007). We aimed to take the advantage of this ultrafast electrontransfer process in fabricating photovoltaic devices, that is, our target was to make use of the electrontransfer process so that exciton dissociation may occur at each and every quantum dot. To do so, we 
introduced some hybrid core-shell nanocrystals with an inorganic nanocrystal in the core and a layer of organic molecules as a shell layer. Upon photoillumination, a photoinduced electron-transfer process was expected to occur from the inorganic core to an organic molecule on the shell resulting in exciton dissociation. With the hybrid core-shell nanocrystals in a hole-transporting polymer matrix, it is expected to have movement of electrons and holes towards the opposite electrodes that have different workfunctions. In this way, we aim to convert the ultrafast photoinduced electron-transfer process into shortcircuit current in the external circuit for efficient hybrid photovoltaic solar cells. Here, we choose the shell molecules in such a way that they formed a homogeneous interface with the host polymer. Moreover, the organic molecules formed type-II bandalignment or a staggered gap with the quantum dots, so that electron-transfer process becomes efficient. In other words, the semiconducting quantum dots decorated with suitable organic molecules can be considered as novel hybrid materials for efficient solar energy harvester (Guchhait and Pal, 2010; Guchhait et al., 2009). A schematic representation of hybrid core-shell formation has been shown in Fig. 4A. While formation of hybrid core-shell structures was studied through optical absorption spectroscopy (Fig. 4B), photoinduced electron-transfer from the core to the shell was manifested by quenching of photoluminescence emission of the nanocrystals (Fig. 4C). The electro-transfer process upon formation of the organic shell layer was further supported by a sharp decrease in photoluminescence lifetime measured through time-correlated single photon counting (TCSPC) measurements spectroscopy.

Fig. 5A depicts a schematic representation of the device structure. Fig. 5B shows the results from a device where only $\mathrm{CdSe}$ nanoparticles were used. Results from the device based on hybrid core-shell nanoparticles are shown in Fig. 5C. In both the cases, we have added $I-V$ characteristics under dark condition that were rectifying in nature. From the results under white light illumination, we find that with the use of hybrid core-shell nanoparticles, the device performance improved to a large extent. The shortcircuit current of the latter device increased by 10
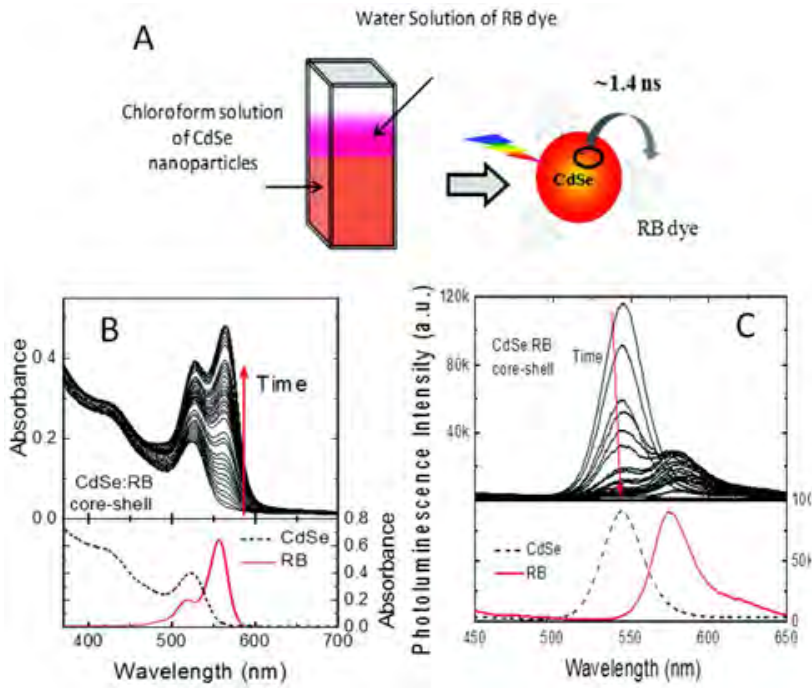

Fig. 4: A: Schematic presentation of hybrid core-shell formation, B: absorbance spectra of hybrid core-shell nanoparticles and $C$ : photoluminescence spectra of the hybrid core-shell naoparticles. In (B) and (C), red arrows indicate time evolution. Source: Guchhait et al. (2009)
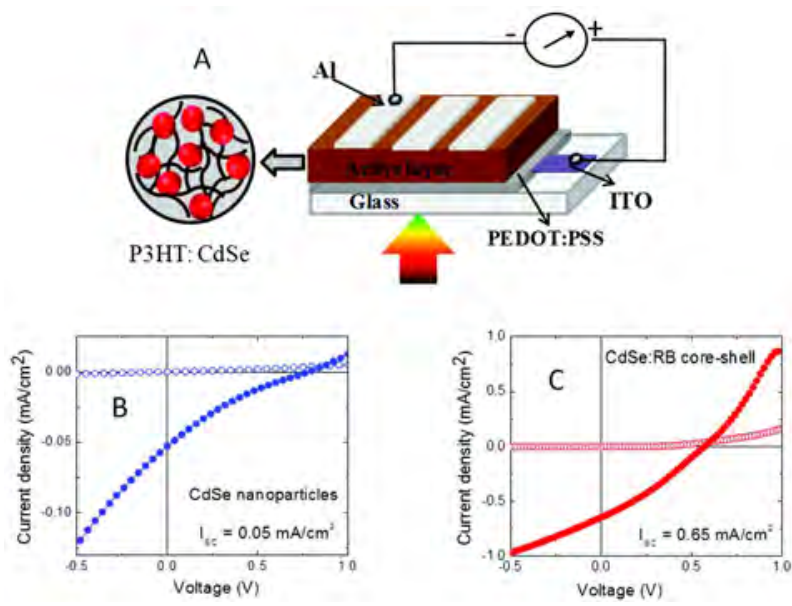

Fig. 5: A: Schematic presentation of a bulk heterojunction device. Current-voltage characteristics of a device based on B: only CdSe nanoparticles and C: CdSe$R B$ hybrid-core shell nanoparticles in $P_{3} H T$ matrix under dark and white light illumination conditions. Source: Guchhait et al., 2009

times as compared to that for the device with only CdSe nanoparticles.

We also observed that the rate of photoinduced electron-transfer process depends on the amount of dye present on the nanoparticle surface as well as on 
the electron-accepting nature of the dye molecules. The rate of photoinduced electron-transfer process has been found to depend on the electron-accepting nature of the organic dye molecules in the shell layer. The device performance accordingly depended on the electron-transfer process. A one-to-one correspondence has been observed between the efficiency of the photovoltaic devices and the electronaccepting nature of the organic dye molecule (or decrease in lifetime of photoluminescence emission) of hybrid core-shell nanocrystals.

From the discussion, we could infer that introduction of hybrid core-shell nanoparticles in photovoltaic devices facilitates the use of inorganic nanoparticles in solar cell applications. Recently, researchers have introduced a range of hybrid nanocomposites in this direction. For example, Chang et al. have reported CdTe/SWNT nanostructures; photoinduced current in such nanostructures could be tuned by tailoring the nature of the semiconductor, morphology, and diameter of the CdTe nanostructures (Chang et al., 2013). Mariani et al. have reported three-dimensional core-shell nanostructure for solar cell applications by using air-stable poly $(3,4-$ ethylenedioxythiophene) (PEDOT) as a shell to periodic GaAs nanopillar arrays (Mariani et al., 2012).

\section{Organic/inorganic Hybrid pn-junctions}

In the field of photovoltaic solar cells, researchers also search for environment-friendly or nontoxic elements with earth-abundance in fabricating highefficient devices. The paths to achieve such a goal are not always unique, that is, a high-efficient device may often contain toxic elements, or green materials may not always return best solar cell parameters. Moreover, easiness of film-formation process should also be considered while choosing materials for fabricating solar cells. Finally, the mechanism of device-operation has remained worth-studying so that directions to improve device-performance can always be sought.

In such a complex scenario, new materials often bring fresh hopes. Earth-abundant $\mathrm{Cu}_{2} \mathrm{ZnSnS}_{4}$ (CZTS) emerged as a promising absorber for thin-film solar cells (Shin et al., 2013). CZTS is a quaternary kesterite semiconductor with a direct band gap $(\sim 1.5 \mathrm{eV})$ and a large absorption coefficient $\left(\sim 10^{4} \mathrm{~cm}^{-1}\right)$. Thin-films of CZTS can be formed through various approaches. IBM Research (Yorktown, New York, USA) has already achieved the PCE of $11.1 \%$ in CZTS thinfilm solar photovoltaic cells. The company also believes that these cells can be manufactured using ink-based techniques including printing or casting (http://www.solarserver.com, 2012). In the lab scale, thin films of $p$-type CZTS have generally been used in conjunction with a layer of $n$-type semiconductors such as CdS to fabricate $p n$-junction solar cells (Tanaka et al., 2009). Recently, we have formed a $p n$-junction between a $p$-type CZTS layer and a fullerene derivative as the $n$-type material so that a solution-processed solar cell can be fabricated with materials based on earth-abundant and nontoxic elements that are more-importantly cadmium-free (Saha et al., 2012). The junction can be termed as a hybrid $p n$-junction between layers of an inorganic semiconductor and an organic semiconductor. Here, we report characterization of CZTS/fullerene hybrid junctions under dark and illumination conditions evidencing solar cell applications to comment on the depletion region formed in $p n$-junction solar cells.

We have characterized the $p n$-junction devices based on CZTS nanoparticles and PCBM molecules. Schematic presentation of a $p n$-junction device structure and the equilibrium band-bending of the junction are shown in Fig. 6A\&B, respectively. During the deposition of CZTS film, we have replaced the long-chain oleylamine ligands with short-chain pyridine by the layer-by-layer technique. This facilitated carrier transport through the CZTS nanoparticle film. In Fig. 6C\&D, we have presented some results based on CZTS/PCBM junctions. In these ITO/CZTS/ $\mathrm{PCBM} / \mathrm{Ca} / \mathrm{Al}$ devices under an illumination condition, excitons were photogenerated in both CZTS and PCBM layers. The excitons, which were generated within the depletion region at the CZTS/PCBM interface, would become easily dissociated into free carriers; the excitons, which are generated within the quasi-neutral region, might diffuse to the junction and become dissociated. Finally, the electrons move through the PCBM layer to the $\mathrm{Ca} / \mathrm{Al}$ electrode and holes move through the CZTS layer to the ITO 


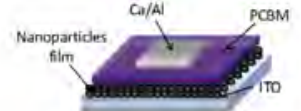

A

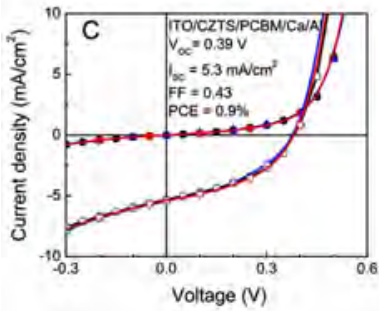

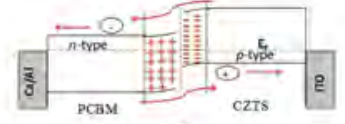

B

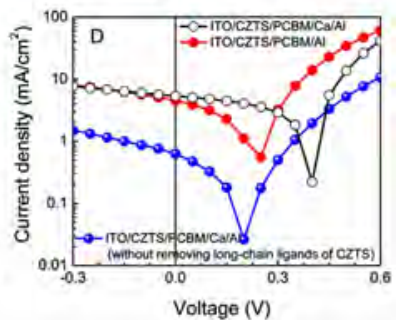

Fig. 6: A: Schematic presentation of a bilayer $p$ n-junction device, B: energy band-bending of the junction under an equilibrium condition, $C$ : current-voltage characteristics of the ITO/CZTS/PCBM/Ca/Al pnjunction device under dark and illumination conditions and D: characteristics under light of different devices as specified in the legend. Source: Saha et al. (2012)

electrode and yield photocurrent in the external circuit.

From $C$ - $V$ characteristics, we have determined the width of the depletion region and the density of carriers at the junction. A depleted and wider depletion-region has been observed in the CZTS/ PCBM $p n$-junction as compared to those in Schottky devices. The results evidenced solar cell applications from nontoxic and earth-abundant materials forming hybrid $p n$-junctions.

\section{pn-Junction Solar Cells Based on Inorganic Nanocrystals}

Solar cells can also be fabricated on basis of only inorganic nanocrystals, so that issues related to degradation of organic semiconductors do not arise. In this direction, we grew solar cells based on a layer of $p$-type nanocrystals and another layer of $n$-type nanocrystals to form a $p n$-junction. In such a junction under an illumination condition, separation of charge carriers occurs due to a drift of minority carriers through the depletion region. We hence formed a fullydepleted $p n$-junctions so that additional materials near the electrodes ("dead zones") could be eliminated that would otherwise have increased the internal resistance of the solar cells without contributing to any photovoltaic response (Dasgupta et al., 2014). In Fig.
7, we show that a fully-depleted device yields an improved solar cell performance as compared to thicker $p n$-junction devices comprising "dead zones". Schematic representations of equilibrium band-bending of CZTS/AgInS $S_{2} @ \mathrm{Cu} p n$-junction device structure and the fully depleted $p n$-junction are also shown.

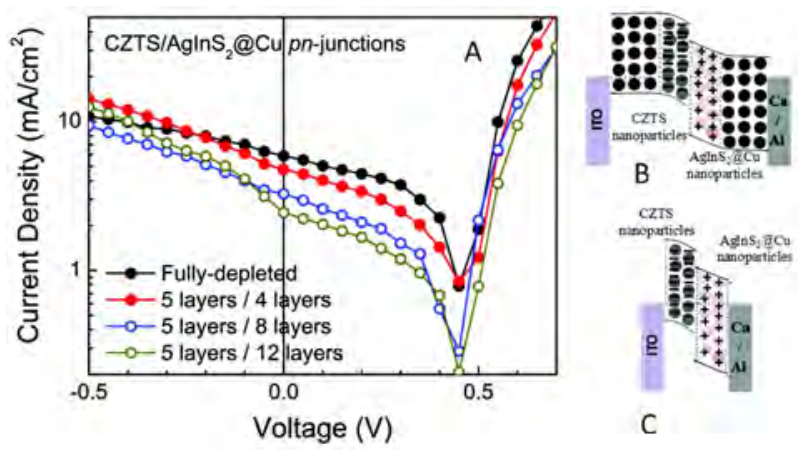

Fig. 7: Current-voltage characteristics of a fully-depleted and three other CZTS/AgInS ${ }_{2} @ \mathrm{Cu} p n$-junctions under an illumination condition. Schematic representations of a conventional $p n$-junction and a fully-depleted $p n$-junction solar cell are also shown. Source: Dasgupta et al. (2014)

\section{Future Avenues}

As we must explore each and every form of renewable energy source, we must also continue to improve manufacturing/development of all types of solar cells. For the first generation solar cells, instead of aiming to improve efficiencies that may have reached saturation, reduction of the manufacturing-cost should be the goal. For the second generation solar cells, an improvement in efficiency would be beneficial to reduce the $\$ / \mathrm{W}$ value so that supply to the grid becomes economical. For the third and fourth generation solar cells, selection of suitable materials through materials engineering and at the same time simplifying the fabrication process of large-area solar cells are the two major directions that researchers should work in tandem.

As in other devices, the missing link between the lab and the plant has to be bridged. When a critical mass of researchers starts to work in this fascinating field, we will be able to comply with the societal aspect of research by making the renewable source of electricity a reality. 


\section{Conclusions}

In conclusion, we have reviewed the evolution of solar (photovoltaic) cells based on a series of materials over the years. Solar cell materials ranging from crystalline silicon to most-recent inorganic quantum dot vs. organic hybrid systems for nanophotovoltaics have been discussed. We have shown how newer materials and materials engineering have allowed researchers to look beyond silicon as material for the future of solar cell technology. The importance of using earth-

\section{References}

Albrecht S, Janietz S, Schindler W, Frisch J, Kurpiers J, Kniepert J, Inal S, Pingel P, Fostiropoulos K, Koch N and Neher D (2012) Fluorinated copolymer PCPDTBT with enhanced open-circuit voltage and reduced recombination for highly efficient polymer solar cells J Am Chem Soc 134 1493214944

Binks D J (2011) Multiple exciton generation in nanocrystal quantum dots - controversy, current status and future prospects Phys Chem Chem Phys 13 12693-12704

Boulesbaa A, Issac A, Stockwell D, Huang Z, Huang J, Guo J and Lian T (2007) Ultrafast charge separation at CdS quantum dot/rhodamine B molecule interface J Am Chem Soc 129 15132-15133

Brabec C J, Sariciftci N S and Hummelen J C (2001) Plastic solar cells Adv Funct Mater 11 15-26

Britt J and Ferekides C (1993) Thin-film CdS/CdTe solar-cell with 15.8-percent efficiency Appl Phys Lett 62 2851-2852

Burschka J, Pellet N, Moon S J, Humphry-Baker R, Gao P, Nazeeruddin M K and Gratzel M (2013) Sequential deposition as a route to high-performance perovskitesensitized solar cells Nature 499 316-319

Carlson D E and Wronski C R (1976) Amorphous silicon solarcell Appl Phys Lett 28 671-673

Chang C H, Jung H, Rheem Y, Lee K H, Lim D C, Jeong Y, Lim J H and Myung N V (2013) Electrochemical synthesis of CdTe/SWNT hybrid nanostructures and their tunable electrical and optoelectrical properties Nanoscale 5 16161623

Chapin D M, Fuller C S and Pearson G L (1954) A new silicon p$\mathrm{n}$ junction photocell for converting solar radiation into electrical power J Appl Phys 25 676-677

Cui D H, Xu J, Zhu T, Paradee G, Ashok S and Gerhold M (2006) Harvest of near infrared light in $\mathrm{PbSe}$ nanocrystal-polymer abundant elements in choosing active materials for solar cells has been discussed to reduce the cost/Watt of electricity. Also, the need for using non-toxic elements in the selection of the active materials has been discussed in order to achieve environmentfriendly and industrially viable solar cells for the future.

\section{Acknowledgements}

The authors gratefully acknowledge financial assistance from SERIIUS, DST, and DeitY projects.

hybrid photovoltaic cells Appl Phys Lett 88183111

Dasgupta U, Saha S K and Pal A J (2014) Fully-depleted pnjunction solar cells based on layers of $\mathrm{Cu}_{2} \mathrm{ZnSnS}_{4}$ (CZTS) and copper-diffused $\mathrm{AgInS}_{2}$ ternary nanocrystals $\mathrm{Sol}$ Energy Mater Sol Cells 124 79-85

Dayal S, Kopidakis N, Olson D C, Ginley D S and Rumbles G (2009) Photovoltaic devices with a low band gap polymer and CdSe nanostructures exceeding 3\% efficiency Nano Lett 10 239-242

Gratzel M (2001) Photoelectrochemical cells Nature 414 338344

Green M A, Emery K, King D L, Igari S and Warta W (2005) Solar cell efficiency tables (version 25) Prog Photovoltaics 13 49-54

Guchhait A, Rath A K and Pal A J (2009) Hybrid core-shell nanoparticles: Photoinduced electron-transfer for charge separation and solar cell applications Chem Mater 21 52925299

Guchhait A and Pal A J (2010) Correlation between photoinduced electron transfer and photovoltaic characteristics in solar cells based on hybrid core-shell nanoparticles J Phys Chem C 114 19294-19298

Hines M A and Scholes G D (2003) Colloidal PbS nanocrystals with size-tunable near-infrared emission: Observation of post-synthesis self-narrowing of the particle size distribution Adv Mater 15 1844-1849

Holder E, Tessler N and Rogach A L (2008) Hybrid nanocomposite materials with organic and inorganic components for optoelectronic devices J Mater Chem 18 1064-1078

http://www.epia.org/home/ (2012) European Photovoltaic Industry Association "Market Report 2011"

http://www.nrel.gov/ncpv/ (2014) Best Research-Cell Efficiencies http://www.solarplaza.com/top10-crystalline-module-efficiency/ (2012) Top 10 World's Most Efficient Solar PV Modules 
(Mono-Crystalline)

http://www.solarserver.com (2012) IBM Research develops 11\% efficient CZTS PV cell

Huynh W U, Dittmer J J and Alivisatos A P (2002) Hybrid nanorod-polymer solar cells Science 295 2425-2427

Ip A H, Thon S M, Hoogland S, Voznyy O, Zhitomirsky D, Debnath R, Levina L, Rollny L R, Carey G H, Fischer A, Kemp K W, Kramer I J, Ning Z, Labelle A J, Chou K W, Amassian A and Sargent E H (2012) Hybrid passivated colloidal quantum dot solids Nat Nanotechnol 7 577-582

Kamat P V (2008) Quantum dot solar cells Semiconductor nanocrystals as light harvesters J Phys Chem C 11218737 18753

Keis K, Magnusson E, Lindstrom H, Lindquist S E and Hagfeldt A (2002) A 5\% efficient photo electrochemical solar cell based on nanostructured $\mathrm{ZnO}$ electrodes Sol Energy Mater Sol Cells 73 51-58

Kim H S, Lee C R, Im J H, Lee K B, Moehl T, Marchioro A, Moon S J, Humphry-Baker R, Yum J H, Moser J E, Gratzel $\mathrm{M}$ and Park N G (2012) Lead iodide perovskite sensitized all-solid-state submicron thin film mesoscopic solar cell with efficiency exceeding 9\% Sci Rep 2591

Kuo C Y, Tang W C, Gau C, Guo T F and Jeng D Z (2008) Ordered bulk heterojunction solar cells with vertically aligned $\mathrm{TiO}(2)$ nanorods embedded in a conjugated polymer Appl Phys Lett 93033307

Kuwabara T, Kawahara Y, Yamaguchi T and Takahashi K (2009) Characterization of inverted-type organic solar cells with a $\mathrm{ZnO}$ layer as the electron collection electrode by ac impedance spectroscopy ACS Appl Mater Interfaces 1 2107-2110

Law M, Greene L E, Johnson J C, Saykally R and Yang P D (2005) Nanowire dye-sensitized solar cells Nat Mater 4 455-459

Lee M M, Teuscher J, Miyasaka T, Murakami T N and Snaith H J (2012) Efficient hybrid solar cells based on mesosuperstructured organometal halide perovskites Science 338 643-647

Li G, Shrotriya V, Huang J S, Yao Y, Moriarty T, Emery K and Yang Y (2005) High-efficiency solution processable polymer photovoltaic cells by self-organization of polymer blends Nat Mater 4 864-868

Liu M Z, Johnston M B and Snaith H J (2013) Efficient planar heterojunction perovskite solar cells by vapour deposition Nature 501 395-398

Lutich A A, Jiang G, Susha A S, Rogach A L, Stefani F D and Feldmann J (2009) Energy transfer versus charge separation in type-II hybrid organic-inorganic nanocomposites Nano
Lett 9 2636-2640

Mariani G, Wang Y, Wong P S, Lech A, Hung C H, Shapiro J, Prikhodko S, El-Kady M, Kaner R B and Hufraker D L (2012) Three-dimensional core-shell hybrid solar cells via controlled in situ materials engineering Nano Lett 12 35813586

Nozik A J (2002) Quantum dot solar cells Physica E 14 115-120

Olson J M, Kurtz S R, Kibbler A E and Faine P (1990) A 27.3percent efficient $\mathrm{Ga}_{0.5} \mathrm{In}_{0.5} \mathrm{P} / \mathrm{GaAs}$ tandem solar-cell Appl Phys Lett 56 623-625

Oregan B and Gratzel M (1991) A low-cost, high-efficiency solarcell based on dye-sensitized colloidal $\mathrm{TiO}_{2}$ films Nature $353737-740$

Panthani M G, Akhavan V, Goodfellow B, Schmidtke J P, Dunn L, Dodabalapur A, Barbara P F and Korgel B A (2008) Synthesis of $\mathrm{CuInS}_{2}, \mathrm{CuInSe}{ }_{2}$, and $\mathrm{Cu}\left(\mathrm{In}_{\mathrm{x}} \mathrm{Ga}_{1-\mathrm{x}}\right) \mathrm{Se}_{2}(\mathrm{CIGS})$ nanocrystal "inks" for printable photovoltaics J Am Chem Soc 130 16770-16777

Park S H, Roy A, Beaupre S, Cho S, Coates N, Moon J S, Moses D, Leclerc M, Lee K and Heeger A J (2009) Bulk heterojunction solar cells with internal quantum efficiency approaching 100\% Nat Photonics 3 297-302

Peet J, Kim J Y, Coates N E, Ma W L, Moses D, Heeger A J and Bazan G C (2007) Efficiency enhancement in low-bandgap polymer solar cells by processing with alkane dithiols $\mathrm{Nat}$ Mater 6 497-500

Peumans P, Yakimov A and Forrest S R (2003) Small molecular weight organic thin-film photodetectors and solar cells $J$ Appl Phys 93 3693-3723

Ray S, De S C and Barua A K (1988) Characterization of microcrystalline silicon films prepared by the glowdischarge method under different deposition conditions Thin Solid Films 156 277-285

Saha S K, Guchhait A and Pal A J (2012) $\mathrm{Cu}_{2} \mathrm{ZnSnS}_{4}$ (CZTS) nanoparticle based nontoxic and earth-abundant hybrid pn-junction solar cells Phys Chem Chem Phys 14 80908096

Sastry O S, Dutta V, Mukerjee A K and Chopra K L (1985) Defect analysis in polycrystalline silicon solar-cells $J$ Appl Phys 57 5506-5511

Scharber M C, Wuhlbacher D, Koppe M, Denk P, Waldauf C, Heeger A J and Brabec C L (2006) Design rules for donors in bulk-heterojunction solar cells - Towards $10 \%$ energyconversion efficiency Adv Mater 18 789-794

Shin B, Gunawan O, Zhu Y, Bojarczuk N A, Chey S J and Guha $S$ (2013) Thin film solar cell with $8.4 \%$ power conversion efficiency using an earth-abundant $\mathrm{Cu}_{2} \mathrm{ZnSnS}_{4}$ absorber Prog Photovoltaics 21 72-76 
Shockley W and Queisser H J (1961) Detailed balance limit of efficiency of p-n junction solar cells J Appl Phys 32 510519

Sites J R and Liu X X (1996) Recent efficiency gains for CdTe and $\mathrm{CuIn}_{1-\mathrm{x}} \mathrm{Ga}_{\mathrm{x}} \mathrm{Se}_{2}$ solar cells: What has changed? Sol Energy Mater Sol Cells 41 373-379

Song Y J and Anderson W A (2000) Amorphous silicon/p-type crystalline silicon heterojunction solar cells with a microcrystalline silicon buffer layer Sol Energy Mater Sol Cells 64 241-249

Sun W T, Yu Y, Pan H Y, Gao X F, Chen Q and Peng L M (2008) $\mathrm{CdS}$ quantum dots sensitized $\mathrm{TiO}_{2}$ nanotube-array photoelectrodes J Am Chem Soc 130 1124-1125

Tanaka K, Oonuki M, Moritake N and Uchiki H (2009) $\mathrm{Cu}_{2} \mathrm{ZnSnS}_{4}$ thin film solar cells prepared by non-vacuum processing Sol Energy Mater Sol Cells 93 583-587

Tu H H and Kelley D F (2006) Photoinduced direct electron transfer from InSe to GaSe semiconductor nanoparticles Nano Lett 6 116-122

Wohrle D and Meissner D (1991) Organic solar-cells Adv Mater 3 129-138

Xu J, Yang X, Yang Q-D, Wong T-L, Lee S-T, Zhang W-J and Lee C-S (2012) Arrays of CdSe sensitized $\mathrm{ZnO} / \mathrm{ZnSe}$ nanocables for efficient solar cells with high open-circuit voltage J Mater Chem 22 13374-13379

Yang X N, Loos J, Veenstra S C, Verhees W J H, Wienk M M, Kroon J M, Michels M A J and Janssen R A J (2005) Nanoscale morphology of high-performance polymer solar cells Nano Lett 5 579-583

Yella A, Lee H W, Tsao H N, Yi C Y, Chandiran A K, Nazeeruddin M K, Diau E W G, Yeh C Y, Zakeeruddin S M and Gratzel M (2011) Porphyrin-sensitized solar cells with cobalt (II/ III)-based redox electrolyte exceed 12 percent efficiency Science 334 629-634. 